\title{
WHO European Childhood Obesity Surveillance Initiative: health-risk behaviours on nutrition and physical activity in 6-9-year-old schoolchildren
}

\author{
Trudy MA Wijnhoven ${ }^{1, *}$, Joop MA van Raaij ${ }^{2,3}$, Agneta Yngve ${ }^{4}$, Agneta Siöberg ${ }^{5}$, \\ Marie Kunešová ${ }^{6}$, Vesselka Duleva ${ }^{7}$, Ausra Petrauskiene ${ }^{8}$, Ana I Rito ${ }^{9}$ and João Breda ${ }^{1}$ \\ ${ }^{1}$ Division of Noncommunicable Diseases and Promoting Health through the Life-Course, WHO Regional Office for \\ Europe, UN City, Marmorvej 51, DK-2 100 Copenhagen $\varnothing$, Denmark: ${ }^{2}$ Centre for Nutrition, Prevention and Health \\ Services, National Institute for Public Health and the Environment, Bilthoven, The Netherlands: ${ }^{3}$ Division of Human \\ Nutrition, Wageningen University, Wageningen, The Netherlands: ${ }^{4}$ School of Hospitality, Culinary Arts and Meal \\ Science, Örebro University, Grythyttan, Sweden: ${ }^{5}$ Department of Food and Nutrition and Sport Science, University of \\ Gothenburg, Gothenburg, Sweden: ${ }^{6}$ Obesity Management Centre, Institute of Endocrinology, Prague, Czech \\ Republic: ${ }^{7}$ Department of Food and Nutrition, National Center of Public Health and Analyses, Sofia, Bulgaria: \\ ${ }^{8}$ Department of Preventive Medicine, Lithuanian University of Health Sciences, Kaunas, Lithuania: ${ }^{9}$ National Health \\ Institute Doutor Ricardo Jorge, Lisbon, Portugal
}

Submitted 6 December 2014: Final revision received 29 March 2015: Accepted 13 May 2015: First published online 1 July 2015

\begin{abstract}
Objective: To assess to what extent eight behavioural health risks related to breakfast and food consumption and five behavioural health risks related to physical activity, screen time and sleep duration are present among schoolchildren, and to examine whether health-risk behaviours are associated with obesity.

Design: Cross-sectional design as part of the WHO European Childhood Obesity Surveillance Initiative (school year 2007/2008). Children's behavioural data were reported by their parents and children's weight and height measured by trained fieldworkers. Descriptive statistics and logistic regression analyses were performed. Setting: Primary schools in Bulgaria, Lithuania, Portugal and Sweden; paediatric clinics in the Czech Republic.

Subjects: Nationally representative samples of 6-9-year-olds ( $n 15$ 643).

Results: All thirteen risk behaviours differed statistically significantly across countries. Highest prevalence estimates of risk behaviours were observed in Bulgaria and lowest in Sweden. Not having breakfast daily and spending screen time $\geq 2 \mathrm{~h} / \mathrm{d}$ were clearly positively associated with obesity. The same was true for eating 'foods like pizza, French fries, hamburgers, sausages or meat pies' $>3 \mathrm{~d}$ /week and playing outside $<1 \mathrm{~h} / \mathrm{d}$. Surprisingly, other individual unhealthy eating or less favourable physical activity behaviours showed either no or significant negative associations with obesity. A combination of multiple less favourable physical activity behaviours showed positive associations with obesity, whereas multiple unhealthy eating behaviours combined did not lead to higher odds of obesity.

Conclusions: Despite a categorization based on international health recommendations, individual associations of the thirteen health-risk behaviours with obesity were not consistent, whereas presence of multiple physical activity-related risk behaviours was clearly associated with higher odds of obesity.
\end{abstract}

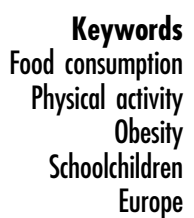

The determinants of childhood obesity are complex and numerous $^{(1)}$. Mostly, it is generally accepted that individual eating and physical activity patterns as well as sedentary behaviours are important contributors ${ }^{(2)}$. Alongside an increase of overweight and obesity levels in children observed during the last decades at the global ${ }^{(3-5)}$ and European levels ${ }^{(2,6)}$, in many countries a shift has been observed from diets based mainly on unprocessed foods to diets high in fat, sugar and salt ${ }^{(7)}$. Simultaneously, trends towards decreased habitual physical activity levels and increased sedentary behaviours (such as screen time) have been observed ${ }^{(7)}$. Lifestyle behaviours related to diet 
and physical activity tend to track from childhood into adulthood $^{(8)}$ and children with excess body weight are likely to stay overweight or obese in adulthood ${ }^{(9)}$. Obesity preventive measures aiming to improve diets and physical activity would thus be priority actions during childhood $^{(1,6)}$.

Monitoring dietary patterns and physical activity levels would ideally be part and parcel of an obesity surveillance system $^{(10)}$ and is important for evaluating policy implementation and combating the obesity epidemic ${ }^{(2)}$. The European Childhood Obesity Surveillance Initiative (COSI) was initiated in 2006 by the WHO Regional Office for Europe and some Member States as a follow-up to the WHO European Charter on Counteracting Obesity ${ }^{(11)}$. COSI is a population-based monitoring system that measures at regular intervals the levels of overweight and obesity (based on mandatory measurements of the children's weight and height) among primary-school children aged $6-9$ years in the WHO European Region. The COSI protocol also includes the administration on a voluntary basis of a family form that gathers information on children's lifestyle behaviours such as food consumption frequency, physical activity, screen time and sleep duration, as well as on family socio-economic characteristics. Countries could choose all or just some of the questions in this family form ${ }^{(12)}$. The first COSI data collection round took place in school year 2007/2008 in which thirteen countries (Belgium (Flemish region only), Bulgaria, Cyprus, Czech Republic, Ireland, Italy, Latvia, Lithuania, Malta, Norway, Portugal, Slovenia and Sweden) participated. All these countries except Cyprus had a complete set of children's data on weight and height measurements, and five countries also had a complete set of children's data on dietary intake and physical activity indicators. The present paper describes the findings of these five countries (Bulgaria, Czech Republic, Lithuania, Portugal and Sweden) that collected data on all questions related to children's lifestyle behaviours on the family form and provided their data to $\mathrm{WHO}$ according to the COSI protocol ${ }^{(13)}$.

The purposes of the current study were to assess to what extent behavioural health risks related to diet and physical activity are present among 6-9-year-old children in five European countries and to examine whether health-risk behaviours are associated with overweight and obesity.

\section{Methods}

\section{Sampling of children}

Countries applied a nationally representative schoolbased cluster sampling design, whereby primary schools were the primary sampling units (except the Czech Republic, where the primary sampling unit was composed of paediatric clinics). Primary schools were selected randomly from the list of all primary schools centrally available in each country through the Ministry of
Education or the national school registry (or in the Czech Republic, the national list of primary-care paediatricians). Anthropometric outcome measures, such as BMI, were the initial main outcomes of interest of COSI implementation. Stratification of the primary sampling units was therefore applied if it was expected that differences in these measures across strata would be observed. This was done by the Czech Republic by region and level of urbanization and by Lithuania by district and level of urbanization. Information on the urbanization grade of the children's residence, using the three predefined options 'urban', 'semi-urban' or 'rural' in all countries, was obtained. Classes formed the secondary sampling units and subsequently all children registered in the sampled classes were approached for their participation. Detailed sampling characteristics have been described elsewhere ${ }^{(12,14)}$.

COSI targets children aged 6, 7, 8 and 9 years old, whereby countries could choose one or more of these four age groups. If all children of the specifically targeted age group were in the same grade, then one class per school was drawn within a grade level. If the specifically targeted age group was spread across grades, however, all grades where children from this age group were present could be sampled. The majority of the thirteen countries that participated in the first data-collection round targeted one age group, including the five countries that are the subject of the present paper's research. Bulgaria, the Czech Republic, Lithuania and Portugal targeted 7-year-olds and Sweden targeted 7- and 8-year-olds. All children in the sampled classes who were younger than 6 years or older than 9 years were excluded from the analyses ( $n$ 18). Moreover, data from Madeira, collected one year after the other Portuguese regions, were not included in the present Portuguese data.

\section{COSI family record form}

The COSI family record form was based partly on the questionnaire used in the 2001/2002 round of the Health Behaviour in School-aged Children (HBSC) study that surveys 11-, 13- and 15-year-olds ${ }^{(15)}$. The form was given directly to the parents, sent home with the child or mailed to the child's home, and it was often attached to the letter informing parents about the survey and asking for their consent. The form was completed by the children's parents or caregivers, possibly together with their child. Table 1 lists the questions and their predefined answer options that were included in the form to collect data on the children's lifestyle behaviours and on parental socio-economic status by describing their educational and occupational level, and were subject of the present paper's research. A complete overview of all questions that were included in the COSI family record form can be found elsewhere ${ }^{(12)}$. For the paper's statistical analyses, the answer options of the children's related items were categorized into 'healthy 
Table 1 Questions and their predefined answer options as included in the COSI family record form to collect data on children's lifestyle behaviours and parental socio-economic status, and categorization of the answer options for the paper's analyses

\section{Questions \\ Items on children \\ Breakfast consumption frequency \\ 'Over a typical or usual week, how often does your child have breakfast?' \\ Food consumption frequency \\ 'Over a typical or usual week, how often does your child eat or drink the following kinds of foods or beverages?' \\ (i) 'Fresh fruit'; (ii) '100\% fruit juice'; (iii) 'vegetables \\ (excluding potatoes)'; (iv) 'soft drinks containing sugar'; \\ (v) 'foods like potato chips (crisps), corn chips, popcorn or peanuts'; (vi) 'foods like candy bars or chocolate'; (vii) 'foods like biscuits, cakes, doughnuts or pies'; (viii) 'foods
like pizza, French fries (chips), hamburgers, sausages or meat pies'}

Physical activity

How does your child usually get to and from school? Please tick one box for "Going to school" and one box for "Coming from school"'

'Is your child a member of one or more sports or dancing clubs (e.g. football, running, hockey, swimming, tennis, basketball, gymnastics, ballet, fitness, ballroom

dancing, etc.)?'

'Over a typical or usual week, on how many days does your child go to this/these sports or dancing club(s)?'

'In his/her free time, about how many hours per day does your child usually play outside, at home or somewhere else? Please tick one box for weekdays and one box for weekends'

\section{Screen time}

'In his/her free time, about how many hours per day does your child usually spend using a computer for playing games (other than homework), at home or somewhere else? Please tick one box for weekdays and one box for weekends'

Answer options

Categorization of answer options for the paper's analyses

'Every day'; 'most days (4-6 days)'; 'some days (1-3 days)'; 'never'

'Every day'; 'most days (4-6 days)'; 'some days ( $1-3$ days)';' never'

'S/he usually takes the school bus'; 's/he usually goes by public transport'; 's/he is usually brought by car'; 's/he usually rides a bicycle'; 's/he usually walks'; 'other'

'Yes'; 'no'

'0 days a week'; ' 1 day a week'; ' 2 days a week'; ' 3 days a week'; ' 4 days a

week'; ' 5 days a week'; ' 6 days a week'; ' 7 days a week'

'Never'; 'less than 1 hour per day'; 'about 1 hour per day'; 'about 2 hours per day'; 'about 3 or more hours

per day'

'Never'; 'less than 1 hour per day'; 'about 1 hour per day'; 'about 2 hours per day'; 'about 3 or more hours per day'
$\Rightarrow$ Every day $\neq=$ 'every day'

$\Rightarrow<7 \mathrm{~d} /$ week $\S=$ 'most days (4-6 days)', 'some days (1-3 days)' or 'never'

Food items (i) to (iii)ll:

$\Rightarrow$ Every day $\neq=$ 'every day'

$\Rightarrow<7 \mathrm{~d} /$ week $\S$ = 'most days (4-6 days)', 'some days (1-3 days)' or 'never' Food items (iv) to (viii):

$\Rightarrow \leq 3 \mathrm{~d} /$ week $\neq=$ 'some days ( $1-3$ days)' or 'never'
$\Rightarrow>3 \mathrm{~d} /$ week $\$=$ 'every day' or 'most days ( $4-6$ days)'

$\Rightarrow$ Active (both routes) $\ddagger=$ 's/he usually rides a bicycle' or 's/he usually walks' $\Rightarrow$ Inactive (both routes)§= 's/he usually takes the school bus', 's/he usually goes by public transport', 's/he is usually brought by car' or other means of inactive transport

$\Rightarrow$ Combined (one route 'active' and one route 'inactive')

$\Rightarrow \geq 2 \mathrm{~d} /$ week $\ddagger$ = '2 days a week', ' 3 days a week', ' 4 days a week', ' 5 days a week', ' 6 days a week' or ' 7 days a week'

$\Rightarrow<2 \mathrm{~d} /$ week $\S=$ '0 days a week', ' 1 day a week' or 'not being a member of one or more sports or dancing club(s)'

\section{$\Rightarrow \quad \geq 1 \mathrm{~h} / \mathrm{d} \neq, \mathfrak{q}$}

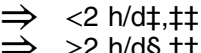




\begin{tabular}{|c|c|c|}
\hline Questions & Answer options & Categorization of answer options for the paper's analyses \\
\hline $\begin{array}{l}\text { 'In his/her free time, about how many hours per day does } \\
\text { your child usually spend watching television (including } \\
\text { videos), at home or somewhere else? Please tick one } \\
\text { box for weekdays and one box for weekends' }\end{array}$ & $\begin{array}{l}\text { 'Never'; 'less than } 1 \text { hour per day'; 'about } \\
1 \text { hour per day'; 'about } 2 \text { hours } \\
\text { per day'; 'about } 3 \text { or more hours } \\
\text { per day' }\end{array}$ & \\
\hline $\begin{array}{l}\text { Sleep duration } \\
\text { 'What is your child's usual amount of sleep each day?' }\end{array}$ & $\begin{array}{l}\text { hours and __minutes (combining } \\
\text { night-time sleep and naps) }\end{array}$ & $\begin{array}{l}\Rightarrow \geq 9 \mathrm{~h} / \mathrm{d} \ddagger \\
\Rightarrow<9 \mathrm{~h} / \mathrm{d} \S\end{array}$ \\
\hline \multicolumn{3}{|l|}{ Items on parents } \\
\hline $\begin{array}{l}\text { 'What is the highest level of education you and/or your } \\
\text { spouse/partner have completed? Please select one } \\
\text { answer only for each of you' }\end{array}$ & $\begin{array}{l}\text { 'Primary school'; 'secondary school'; } \\
\text { 'undergraduate/bachelor's degree'; } \\
\text { 'master's degree or higher' }\end{array}$ & $\begin{array}{l}\text { Maximum educational level of both parents: } \\
\Rightarrow \text { Low }=\text { both parents 'primary school' or 'secondary school' } \\
\Rightarrow \text { High = at least one parent 'undergraduate/bachelor's degree' or 'master's } \\
\text { degree or higher' }\end{array}$ \\
\hline \multicolumn{3}{|l|}{ Occupation } \\
\hline $\begin{array}{l}\text { 'Which of the following best describes your and/or your } \\
\text { spouse's/partner's main work over the last } 12 \text { months? } \\
\text { Please select one answer only for each of you' }\end{array}$ & $\begin{array}{l}\text { 'Government employed'; 'non- } \\
\text { government employed'; 'self- } \\
\text { employed'; 'student'; 'homemaker'; } \\
\text { 'unemployed, able to work'; } \\
\text { 'unemployed, unable to work'; 'retired' }\end{array}$ & $\begin{array}{l}\Rightarrow \text { Both unemployed = both parents 'student', 'homemaker', 'unemployed, } \\
\text { able to work', 'unemployed, unable to work' or 'retired' } \\
\Rightarrow \begin{array}{l}\text { One or both employed = at least one parent 'government employed', 'non- } \\
\text { government employed' or 'self-employed' }\end{array}\end{array}$ \\
\hline
\end{tabular}

CoSI, Childhood Obesity Surveillance Initiative.

†'Healthy behaviour' category, which served as the reference category in the logistic regression analyses.

'Health-risk behaviour' category, which served as the exposure of interest and was used for the calculation of the three risk behaviour scores.

IThe answers for the two items 'fresh fruit' and ' $100 \%$ fruit juice' were combined into 'every day' (at least one of the items was categorized in 'every day') and ' $<7 \mathrm{~d} /$ week' (both items were categorized in ' $<7 \mathrm{~d} /$ week'). INumerical values were assigned to the items 'playing outside on a weekday' and 'playing outside on a weekend day' enabling the conversion of this item to a numerical scale ('never' $=0$; 'less than 1 hour per day' $=0.5$; 'about 1 hour per day' $=1$; 'about 2 hours per day' $=2$; 'about 3 or more hours per day' $=3$ ). Usual outside play time per day was calculated weighing weekday $(5 / 7)$ and weekend hours $(2 / 7)$ accordingly.

'¥Numerical values were assigned to the items 'using a computer 'and 'watching television' on a weekday or a weekend day enabling the conversion of these two items to a numerical scale ('never' $=0$; 'less than 1 hour (2/7) accordingly. 
behaviours' $v$. 'health-risk behaviours' (see also Table 1), whereby the categorization was based on international health recommendations as follows:

1. Breakfast consumption frequency: daily breakfast consumption is part of a healthy diet and contributes to the quality and quantity of a person's daily dietary intake $^{(16)}$ (as such categorized in the 'healthy behaviour category' in the present paper).

2. Food consumption frequency: eight items in the questionnaire related to food consumption frequencies were used for the analyses: (i) 'fresh fruit'; (ii) '100\% fruit juice'; (iii) 'vegetables (excluding potatoes)'; (iv) 'soft drinks containing sugar'; (v) 'foods like potato chips (crisps), corn chips, popcorn or peanuts'; (vi) 'foods like candy bars or chocolate'; (vii) 'foods like biscuits, cakes, doughnuts or pies'; and (viii) 'foods like pizza, French fries (chips), hamburgers, sausages or meat pies'. Items (i) to (iii) are good sources of complex carbohydrates, vitamins, minerals and other substances important for good health ${ }^{(17,18)}$ and one of the main food groups that should contribute to a child's daily diet ${ }^{(19)}$. Daily consumption of these items was considered a 'healthy behaviour' in the present paper. Items (iv) to (viii) tend to have a high content of saturated fats, free sugars or salt, and therefore their consumption should be limited ${ }^{(20)}$. Consumption of these items $\leq 3 \mathrm{~d}$ /week was considered a 'healthy behaviour' in the present paper.

3. Physical activity: children and adolescents aged 5-17 years should accumulate at least $60 \mathrm{~min}$ of moderate- to vigorous-intensity physical activity daily. Most of the daily physical activity should be aerobic. Vigorous-intensity activities should be incorporated, including those that strengthen muscle and bone, at least three times weekly. These WHO recommendations represent a minimum target for daily physical activity that allows for health enhancement and prevention of non-communicable diseases ${ }^{(21)}$. Active transport, playing outside for $\geq 1 \mathrm{~h} / \mathrm{d}$ and performing sport activities for $\geq 2 \mathrm{~d} /$ week are in line with the recommended levels for this age group (as such categorized in the 'healthy behaviour category' in the present paper).

4. Screen time: guidelines for parents from the American Academy of Pediatrics include the limitation of total media time to no more than $1-2 \mathrm{~h} / \mathrm{d}^{(22)}$. Spending screen time $<2 \mathrm{~h} / \mathrm{d}$ was considered a 'healthy behaviour' in the present paper.

5. Sleep duration: according to normal sleep characteristics, the usual sleep duration of pre-school children aged 4 years is $12-13 \mathrm{~h} / \mathrm{d}$ and shows a steady decline with increasing age in schoolchildren aged 5 years onwards. By 10 years of age, the sleep duration is $8-10$ $\mathrm{h} / \mathrm{d}^{(23)}$. Sleep duration of $\geq 9 \mathrm{~h} / \mathrm{d}$ was considered a 'healthy behaviour' in the present paper.
Food and physical activity risk behaviour scores

A 'food-risk behaviour score' and a 'physical activity-risk behaviour score' were created for each child based on the presence of eight food-related and five physical activityrelated (including screen time and sleep duration) healthrisk behaviours, respectively (see Table 1). One point was assigned to the presence of each risk behaviour and subsequently all points were added together. The 'foodrisk behaviour score' could range from 0 (none of the food-risk behaviours present) to 8 points (all food-risk behaviours present), the food-risk behaviours being:

1. having breakfast $<7 \mathrm{~d} /$ week;

2. eating fruit $<7 \mathrm{~d} /$ week;

3. eating vegetables (excluding potatoes) $<7 \mathrm{~d} /$ week;

4. drinking soft drinks containing sugar $>3 \mathrm{~d} /$ week;

5. eating foods like potato chips (crisps), corn chips, popcorn or peanuts $>3 \mathrm{~d} /$ week;

6. eating foods like candy bars or chocolate $>3 \mathrm{~d} /$ week;

7. eating foods like biscuits, cakes, doughnuts or pies $>3$ $\mathrm{d} /$ week; and

8. eating foods like pizza, French fries (chips), hamburgers, sausages or meat pies $>3 \mathrm{~d}$ /week.

The 'physical activity-risk behaviour score' could range from 0 (none of the physical activity-risk behaviours present) to 5 points (all physical activity-risk behaviours present), the physical activity-risk behaviours being:

1. using inactive transportation going to and from school;

2. going to a sports or dancing club $<2 \mathrm{~d}$ /week;

3. playing outside $<1 \mathrm{~h} / \mathrm{d}$;

4. spending screen time $\geq 2 \mathrm{~h} / \mathrm{d}$; and

5. sleep duration $<9 \mathrm{~h} / \mathrm{d}$.

In addition, a 'health-risk behaviour score' was created for each child by combining the 'food-risk behaviour score' and the 'physical activity-risk behaviour score' ranging from 0 (none of the health-risk behaviours present) to 13 points (all health-risk behaviours present). The three scores were assigned only to the children with no missing values for any of the thirteen health-risk behaviours under study.

\section{Weight and height measurements}

Children's weight and height were measured by fieldworkers who were trained in measuring according to WHO standardized techniques ${ }^{(13,24)}$. Children were asked to take off their shoes and socks, as well as all heavy clothing and to remove items such as wallets or mobile phones. The clothes worn by a child during the weight and height measurements were noted by using four predefined types of clothing: 'underwear only', 'gym clothes (e.g. shorts and t-shirt only)', 'light clothing (e.g. t-shirt, cotton trousers or skirt)' or 'heavy clothing (e.g. sweater and jeans)'. Body weight was measured to the nearest $0 \cdot 1 \mathrm{~kg}$ with portable digital (mainly manufacturer-calibrated) scales and body 
height was measured standing upright to the nearest $0 \cdot 1 \mathrm{~cm}$ with portable stadiometers. Body weight was adjusted for the weight of the clothes worn, whereby the average weights of types of clothing were provided by each country. BMI was calculated using the formula: adjusted weight $/$ height $^{2}\left(\mathrm{~kg} / \mathrm{m}^{2}\right)$. The 2007 WHO recommended growth reference ${ }^{(25)}$ for school-age children was used to compute BMI-for-age $Z$-scores. Children who did not have biologically plausible values (i.e. a BMI-for-age $Z$-score between -5 and $+5^{(26)}$ ) were excluded from the analyses ( $n$ 31). Thinness was defined as the proportion of children with a BMI-for-age value $<-2 \quad Z$-score (BMI-for-age value below -2 SD relative to the median BMI-for-age of the 2007 WHO growth reference) ${ }^{(25)}$, normal weight as the proportion of children with a BMI-for-age value $\geq-2$ and $\leq+1$ $Z$-score, overweight as the proportion of children with a BMI-for-age value above $+1 Z$-score, obesity as the proportion of children with a BMI-for-age value above +2 $Z$-score and pre-obesity as the proportion of children with a BMI-for-age value $>+1$ and $\leq+2 Z$-score. The prevalence estimates for overweight children include those who are obese and the prevalence estimates for obese children exclude those who are pre-obese ${ }^{(24)}$. The three physical status categories 'normal weight', 'overweight' and 'obese' were used as outcome measures in the analyses.

\section{Statistical analyses}

For each country-specific data set, the Shapiro-Francia test was used to assess whether the three calculated riskbehaviour scores were normally distributed. Preliminary analyses revealed that all country-specific food-risk behaviour and health-risk behaviour scores were skewed, and thus the final descriptive analyses included the calculation of their medians and quartiles. Mean and standard deviation were computed for continuous normally distributed variables and percentage for categorical variables. Differences in percentages and medians across the countries were examined using the $\chi^{2}$ test and the Kruskal-Wallis test, respectively. If the $\chi^{2}$ tests were found significant, the Marascuilo procedure ${ }^{(27)}$ was used for the multi-group comparisons of proportions between countries.

Bivariate multilevel logistic regression analyses were performed, and odds ratios along with 95\% confidence intervals were obtained by country to explore associations between each of the thirteen children's health-risk behaviours individually (exposure variables) and the odds of being overweight as well as the odds of being obese (compared with normal-weight children). The association was considered positive when a health-risk behaviour was associated with higher odds of the outcome of interest (overweight or obesity), and the association was considered negative when the health-risk behaviour was associated with lower odds of the outcome.
Nine of the preliminary country-specific analyses performed, to test the interaction between the sex of the child and each of the thirteen behaviours associated with overweight or with obesity, indicated that the analyses needed to be stratified by sex. All country-specific final analyses were therefore adjusted for the children's sex and age, and included random effects for the primary sampling units (schools in Bulgaria, Lithuania, Portugal and Sweden; paediatric clinics in the Czech Republic) to account for the clustered study design. The analyses were also done for the five countries together and included the random effects for country as well.

In the multivariable multilevel logistic regression analyses, children from the total study group with a missing value for any of the children's health-risk behaviours ( $n$ 3731), children's residential urbanization grade ( $n$ 77), parental education ( $n$ 1277) or parental occupation were excluded ( $n$ 1710). None of the health-risk behaviours showed multicollinearity, which was tested with Pearson correlation analyses and determined by a correlation coefficient of 0.80 or higher. All health-risk behaviours were included simultaneously in the multivariable analyses and similar adjustments were made as with the bivariate analyses. In addition, the analyses were adjusted for children's residential urbanization grade, parental education and parental occupation because preliminary analyses suggested the presence of an association between each of these three variables individually and children's overweight or obesity in at least one country. This subgroup of children for the multivariable analyses was also used to estimate the odds of being overweight or the odds of being obese being associated with the number of risk behaviours present relative to zero or one of the risk behaviours present. The linear trend test of odds ratios was performed using the likelihood ratio test.

A $P$ value of $<0.05$ was used to define statistical significance. All statistical analyses were performed in the statistical software package Stata version 10·1.

\section{Results}

\section{Children's characteristics}

The initial sample included 19494 children who were present on the day of the measurements and of whom the highest number of refusals was observed in Bulgaria (13.3\%) and Sweden (11.8\%). Of the 18183 children with complete information on age, sex and anthropometric measures, $86 \cdot 3 \%$ returned a filled out COSI family form. The subgroup of children without any missing values for the variables used for the multivariable analyses included in total 5126 fewer children (Bulgaria, 27.4\%; Czech Republic, $32.2 \%$; Lithuania, 29.6 \%; Portugal, 39.9\%; Sweden, 35.5\%) than the total study group of 15643 children.

Table 2 summarizes some children's characteristics in the five countries. In the total study group, mean age 
Table 2 Characteristics of the study population by country: nationally representative samples of 6-9-year-olds, WHO European Childhood Obesity Surveillance Initiative, school year 2007/2008

\begin{tabular}{|c|c|c|c|c|c|}
\hline Characteristic & Bulgaria & Czech Republic & Lithuania & Portugal & Sweden \\
\hline $\begin{array}{l}\text { Children who were present on the day of the } \\
\text { anthropometric measurements: total }(n)\end{array}$ & 3914 & 1695 & 4955 & 3592 & 5338 \\
\hline $\begin{array}{l}\text { Children who participated in the anthropometric } \\
\text { measurements: total }(n) \ddagger\end{array}$ & 3392 & 1695 & 4948 & 3590 & 4708 \\
\hline $\begin{array}{l}\text { Children with complete data on age, sex, weight and } \\
\text { height measures: total }(n)\end{array}$ & 3381 & 1692 & 4939 & 3590 & 4581 \\
\hline Children who returned a filled out family form: total $(n) \S$ & 3427 & 1660 & 4436 & 3063 & 3711 \\
\hline Total study group of children: total $(n) \|$ & 3267 & 1633 & 4084 & 3026 & 3633 \\
\hline \multicolumn{6}{|l|}{ Age (years) } \\
\hline Mean & $7 \cdot 7$ & $7 \cdot 0$ & $7 \cdot 8$ & 7.5 & 8.4 \\
\hline SD & 0.3 & 0.3 & 0.3 & 0.6 & 0.6 \\
\hline \multicolumn{6}{|l|}{ Boys } \\
\hline$n$ & 1619 & 815 & 2064 & 1509 & 1874 \\
\hline$\%$ & $49 \cdot 6$ & 49.9 & $50 \cdot 5$ & $49 \cdot 9$ & 51.6 \\
\hline Prevalence of overweight (\%) & $28 \cdot 8^{\mathrm{b}}$ & $20 \cdot 9^{\mathrm{c}}$ & $23 \cdot 1^{\mathrm{c}}$ & $37 \cdot 6^{\mathrm{a}}$ & $23 \cdot 2^{\mathrm{C}}$ \\
\hline Prevalence of obesity (\%) & $12 \cdot 4^{\mathrm{a}}$ & $7 \cdot 3^{b}$ & $8 \cdot 3^{b}$ & $14 \cdot 6^{\mathrm{a}}$ & $6 \cdot 5^{\mathrm{b}}$ \\
\hline Prevalence of normal weight (\%) & $68 \cdot 4^{\mathrm{b}}$ & $76 \cdot 3^{a}$ & $74.9^{a}$ & $61 \cdot 5^{\mathrm{C}}$ & $75 \cdot 6^{a}$ \\
\hline Prevalence of thinness (\%)ף & $2 \cdot 9^{a}$ & $2 \cdot 8^{a}$ & $2 \cdot 0^{a}$ & $0.9^{\mathrm{b}}$ & $1 \cdot 1^{\mathrm{b}}$ \\
\hline \multicolumn{6}{|l|}{ BMI-for-age Z-score } \\
\hline Mean & 0.35 & $0 \cdot 13$ & 0.27 & 0.71 & 0.27 \\
\hline SD & 1.36 & $1 \cdot 21$ & $1 \cdot 18$ & 1.20 & 1.07 \\
\hline Subgroup of children: total $(n) \neq \ddagger$ & 2373 & 1107 & 2874 & 1818 & 2345 \\
\hline \multicolumn{6}{|l|}{ Age (years) } \\
\hline Mean & $7 \cdot 7$ & $7 \cdot 0$ & $7 \cdot 8$ & 7.5 & 8.4 \\
\hline SD & 0.3 & 0.3 & 0.3 & 0.6 & 0.6 \\
\hline \multicolumn{6}{|l|}{ Boys } \\
\hline$n$ & 1189 & 543 & 1475 & 901 & 1247 \\
\hline$\%$ & $50 \cdot 1$ & $49 \cdot 1$ & $51 \cdot 3$ & $49 \cdot 6$ & 53.2 \\
\hline Prevalence of overweight (\%)ף & $29 \cdot 3^{b}$ & $20 \cdot 1^{c}$ & $24 \cdot 5^{c}$ & $37 \cdot 7^{\mathrm{a}}$ & $22 \cdot 6^{\mathrm{C}}$ \\
\hline Prevalence of obesity (\%) & $12 \cdot 6^{\mathrm{a}}$ & $7 \cdot 4^{\mathrm{b}, \mathrm{c}}$ & $8.9^{b}$ & $13 \cdot 8^{\mathrm{a}}$ & $5 \cdot 8^{\mathrm{c}}$ \\
\hline Prevalence of normal weight (\%)ף & $68 \cdot 1^{\mathrm{b}}$ & $77 \cdot 2^{\mathrm{a}}$ & $73 \cdot 5^{a}$ & $61 \cdot 6^{\mathrm{C}}$ & $76 \cdot 1^{\mathrm{a}}$ \\
\hline Prevalence of thinness (\%) & $2 \cdot 6^{\mathrm{a}}$ & $2 \cdot 7^{\mathrm{a}, \mathrm{b}}$ & $2 \cdot 0^{a, b}$ & $0.7^{\mathrm{c}}$ & $1 \cdot 3^{\mathrm{b}, \mathrm{c}}$ \\
\hline \multicolumn{6}{|l|}{ BMI-for-age Z-score } \\
\hline Mean & 0.38 & 0.13 & 0.30 & 0.70 & 0.25 \\
\hline SD & 1.36 & 1.22 & 1.20 & 1.19 & 1.07 \\
\hline
\end{tabular}

${ }_{\mathrm{a}, \mathrm{b}, \mathrm{c}}$ Proportions within a row with unlike superscript letters were significantly different (Marascuilo procedure). Superscripts are ranked by decreasing prevalence, whereby the highest prevalence was indicated with superscript a.

$\ddagger$ All children who agreed to have their weight and height measured, including children with missing information on age or sex.

$\S$ Out of the children who returned a filled out family form, 3285 Bulgarian, 1649 Czech, 4089 Lithuanian, 3032 Portuguese and 3637 Swedish children had complete information on age, sex, weight and height measures.

IIChildren with complete information on sex, whose age was between 6 and 9 years old, whose weight and height were measured, whose BMI-for-age Z-score was within the normal range $(\geq-5$ and $\leq+5)$ and who returned a filled out family record form.

ๆOverweight is defined as the proportion of children with a BMl-for-age value $>+1$ Z-score (i.e. BMI-for-age above +1 SD relative to the median BMI-for-age of the 2007 WHO growth reference) ${ }^{(25)}$, obesity as the proportion of children with a BMI-for-age value $>+2 Z$-score, normal weight as the proportion of children with a BMI-for-age value $\geq-2$ and $\leq+1 Z$-score, and thinness as the proportion of children with a BMI-for-age value $<-2 Z$-score. Statistically significant difference in proportions across the countries $\left(X^{2}\right.$ test; $\left.P<0.001\right)$.

$\ddagger \ddagger$ All criteria for the total study group of children, as well as no missing values for the thirteen health-risk behaviours, children's residential urbanization grade, parental education and parental occupation.

ranged from $7 \cdot 0$ years in the Czech Republic to $8 \cdot 4$ years in Sweden, and boys and girls were equally represented. The prevalence of overweight ranged from $20 \cdot 9$ to $37.6 \%$ and the prevalence of obesity ranged from 6.5 to $14.6 \%$. The prevalence figures of Czech, Lithuanian and Swedish children did not differ from each other, but their values were statistically significantly lower than those of Bulgarian and Portuguese children. The subgroup of children without missing values on any of the health-risk behaviours, children's residential urbanization grade, parental education and parental occupation showed similar patterns (Table 2).

Outcomes on the educational level and the main occupation over the last 12 months of the children's parents as well as the children's residential urbanization grade are given in Supplementary Table 1 (see online supplementary material). In summary, the percentage of parents with either primary school or secondary school as their highest completed educational level was $37.9 \%$ in Lithuania, $49.3 \%$ in Sweden, $62.0 \%$ in the Czech Republic, $63.2 \%$ in Bulgaria and $80.2 \%$ in Portugal. Unemployment of both parents varied between $2 \cdot 0$ and $3.6 \%$ in the Czech Republic, Lithuania, Portugal and Sweden and was $10.4 \%$ in Bulgaria. The children's residential area was mainly urban in Bulgaria (78.8\%), Portugal (66.4\%) and in the Czech Republic (47.8\%), mainly semi-urban in Lithuania (40.9\%) and mainly rural in Sweden $(55 \cdot 3 \%)$. 


\section{Breakfast and food consumption frequencies}

Supplementary Table 2 (see online supplementary material) presents the proportion of consumption frequencies of breakfast and eight food items over a usual week for each answer category in the five countries. The first part of Table 3 is derived from Supplementary Table 2 and presents the frequencies of food-related health-risk behaviours. As shown in Table 3, the prevalence of all food-related risk behaviours differed statistically significantly across the countries. Less favourable food behaviours (shown by lower-ranked superscripts, e.g. a and b) were mainly found in Bulgaria and more favourable food behaviours in Sweden (shown by higher-ranked superscripts, e.g. d and e). Almost $40 \%$ or more of the Bulgarian children ate foods like 'pizza, French fries (chips), hamburgers, sausages or meat pies', 'biscuits, cakes, doughnuts or pies', 'potato chips (crisps), corn chips, popcorn or peanuts' or 'candy bars or chocolate' on $>3 \mathrm{~d} /$ week, while $6 \%$ or fewer of the Swedish children did so. The percentage of children who did not have breakfast every day ranged from $4.4 \%$ in Portugal to $32.5 \%$ in Lithuania.

\section{Physical activity, screen time and sleep duration}

Supplementary Table 3 (see online supplementary material) presents the proportion of items related to physical activity and screen time for each answer category in the five countries. The second part of Table 3 is derived from Supplementary Table 3 and presents the frequencies of physical activity-related health-risk behaviours. As shown in Table 3, the prevalence of all physical activity-related risk behaviours differed statistically significantly across the countries.
Less favourable physical activity-related behaviours were found in Bulgaria and Portugal and more favourable physical activity-related behaviours mainly in the Czech Republic. The majority of the Bulgarian (79.0\%) and Portuguese $(70.5 \%)$ children did not go to a sports or dancing club at all or only once weekly, and $35 \%$ of the Portuguese children did not play outside for $\geq 1 \mathrm{~h} / \mathrm{d}$. More than $70 \%$ of the Bulgarian and Lithuanian children participated in screen time $\geq 2 \mathrm{~h} / \mathrm{d}$, whereas the percentage in the other three countries ranged between 30 and $40 \%$.

\section{Food and physical activity risk-bebaviour scores}

A food-risk behaviour score of maximum 8 (not favourable on any of the behaviours) was found in $0.2 \%$ of the total subgroup of children ( $n$ 10 517) and a physical activity-risk behaviour score of maximum 5 in $0.3 \%$. A food-risk behaviour score of 0 (favourable on all behaviours) was found in $14.3 \%$ of the total subgroup of children and a physical activity-risk behaviour score of 0 in $7.9 \%$. None of the children had the maximum health-risk behaviour score of 13 and $2 \cdot 2 \%$ of the children had a health-risk behaviour score of 0 . Table 4 displays the median values of the three calculated risk-behaviour scores (based on the presence of food-related and physical activity-related health-risk behaviours). On average, Bulgarian children had the highest food-risk and healthrisk behaviour scores and Swedish children the lowest.

\section{Associations with obesity and overweight}

For the group of children in the five countries, statistically significant bivariate associations (with adjustment for

Table 3 Prevalence (\%) of children's health-risk behaviours in the total study groupł by country: nationally representative samples of 6-9-year-olds, WHO European Childhood Obesity Surveillance Initiative, school year 2007/2008

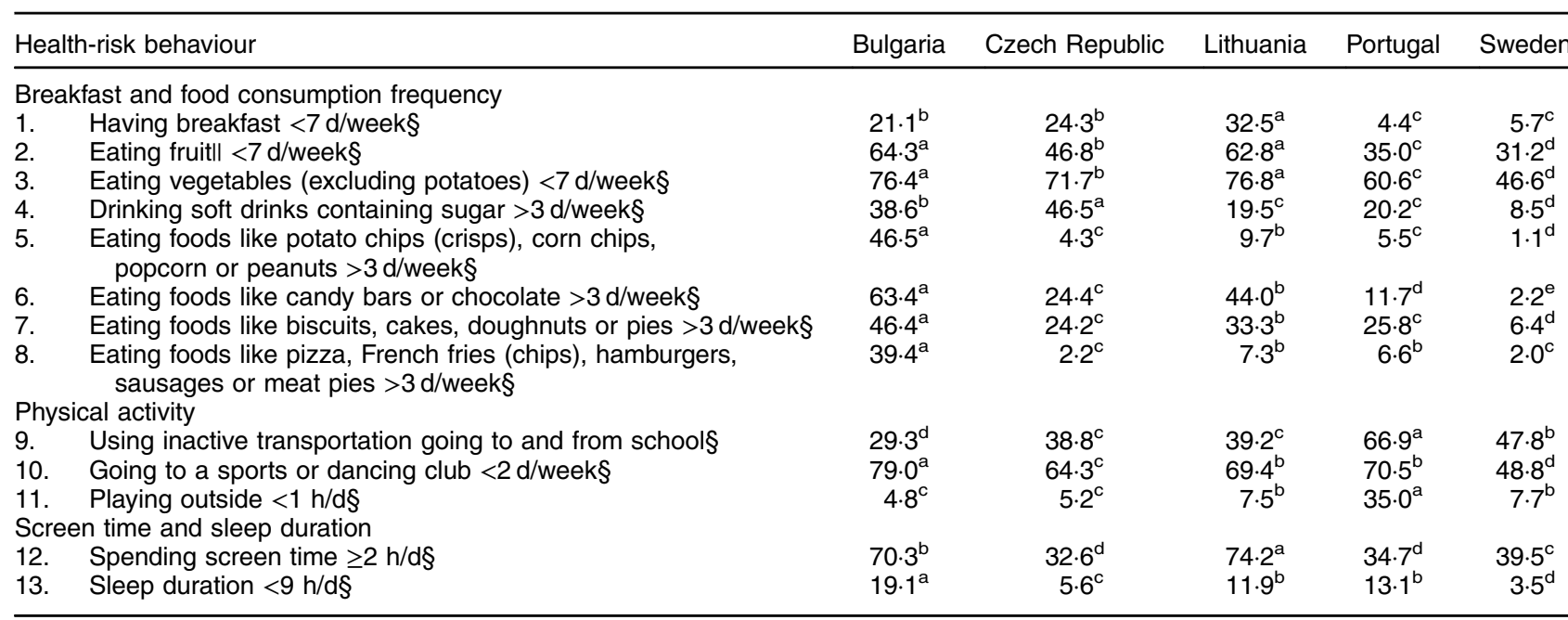

$\mathrm{a}, \mathrm{b}, \mathrm{c}, \mathrm{d}, \mathrm{e}$ Within each health-risk behaviour item, proportions with unlike superscript letters were significantly different (Marascuilo procedure). Superscripts are ranked by decreasing prevalence, whereby the highest prevalence was indicated with superscript a.

$\ddagger$ Children with complete information on sex, whose age was between 6 and 9 years old, whose weight and height were measured, whose BMI-for-age Z-score was within the normal range $(\geq-5$ and $\leq+5)$ and who returned a filled out family record form.

$\S$ Statistically significant difference in proportions across the countries $\left(X^{2}\right.$ test; $\left.P<0.001\right)$.

ICombination of 'fresh fruit' and ' $100 \%$ fruit juice'. 
children's sex and age) with obesity were found in four food-related risk behaviours (Table 5), whereas significant multivariable associations (with adjustment for children's sex and age, all thirteen health-risk behaviours, children's residential urbanization grade, parental education and parental occupation) were seen in five food-related risk behaviours (Table 6). Children were more likely to be obese when they did not have breakfast every day or ate 'foods like pizza, French fries (chips), hamburgers, sausages or meat pies' $>3 \mathrm{~d} /$ week, while children were less likely to be obese when they did not eat fruit every day or ate 'foods like potato chips (crisps), corn chips, popcorn or peanuts' or 'foods like biscuits, cakes, doughnuts or pies' $>3 \mathrm{~d} /$ week (Table 6). Playing outside $<1 \mathrm{~h} / \mathrm{d}$ and spending screen time $\geq 2 \mathrm{~h} / \mathrm{d}$ were the only physical activity-related risk behaviours that were statistically significantly associated with higher odds of obesity in the total group or in a country (in both bivariate and multivariable models).

For the group of children in the five countries, the bivariate analyses for overweight indicated statistically significant associations between the same four foodrelated risk behaviours and overweight as well as between spending screen time $\geq 2 \mathrm{~h} / \mathrm{d}$ and overweight (Supplementary Table 4, see online supplementary material) as were found with the bivariate analyses for obesity (Table 5). The physical activity-related risk behaviour playing outside for $<1 \mathrm{~h} / \mathrm{d}$ was not associated with overweight in both the bivariate and the multivariable analyses. Furthermore, eating 'foods like pizza, French fries (chips), hamburgers, sausages or meat pies' on $>3 \mathrm{~d} /$ week did not lead to statistically significant higher odds of overweight (Supplementary Table 5, see online supplementary material), as was shown with the multivariate analyses for obesity (Table 6).

Table 7 presents the associations between the three calculated risk-behaviour scores and obesity. For the group of children in the five countries, none of the foodrisk behaviour scores showed a statistically significant association with obesity. A country-specific statistically significant positive association between the food-risk behaviour score of 1 and obesity was only found in Sweden, whereas the other scores did not reach the statistical significance level. The physical activity-risk behaviour score showed positive associations with obesity at the total group level, whereby children with a score of 2 to 4 were more likely to be obese than children with a score of 0 . Country-specific positive associations between the physical activity-risk behaviour score and obesity also reached the statistical significance level in Lithuania and Sweden. Compared with children with a combined health-risk behaviour score of 0 or 1 , the higher the score the more likely children were obese in most categories (both in the total group and in Sweden).

Supplementary Table 6 (see online supplementary material) shows the associations between the three 
Table 5 Bivariate associations $\ddagger$ between thirteen health-risk behaviours and obesity in the total study group§, by country: nationally representative samples of 6-9-year-olds, WHO European Childhood Obesity Surveillance Initiative, school year 2007/2008

\section{Health-risk behaviour}

\section{Breakfast and food consumption frequency}

1.II Having breakfast $<7 \mathrm{~d} /$ week

2.II Eating fruit $\|<\mathrm{d} /$ week

3.II Eating vegetables (excluding potatoes) $<7 \mathrm{~d} /$ week

4.II Drinking soft drinks containing sugar $>3 \mathrm{~d} /$ week

5.II Eating foods like potato chips (crisps), corn chips, popcorn or peanuts $>3 \mathrm{~d} /$ week

6.II Eating foods like candy bars or chocolate $>3 \mathrm{~d} /$ week

7.II Eating foods like biscuits, cakes, doughnuts or pies $>3 \mathrm{~d} /$ week

8.II Eating foods like pizza, French fries (chips), hamburgers, sausages or meat pies $>3 \mathrm{~d} /$ week

Physical activity

9.I Using inactive transportation going to and from school

10.ll Going to a sports or dancing club $<2 \mathrm{~d} /$ week

11.II Playing outside $<1 \mathrm{~h} / \mathrm{d}$

Screen time and sleep duration

12.II Spending screen time $\geq 2 \mathrm{~h} / \mathrm{d}$

13.I Sleep duration $<9 \mathrm{~h} / \mathrm{d}$

no observations for obese children.

.

¥All bivariate analyses were adjusted for the children's sex and age and included random effects for the primary sampling units. The analyses for the five countries together also included random effects for country. $\S$ Normal-weight or obese children with complete information on sex, whose age was between 6 and 9 years old, whose weight and height were measured, whose BMI-for-age $Z$-score was within the normal range ( $\geq-5$ and $\leq+5$ ) and who returned a filled out family record form. Obesity is defined as the proportion of children with a BMI-for-age value $>+2$ Z-score (i.e. BMI-for-age above +2 sD relative to the median BMI-for-age of the 2007 WHO growth reference) ${ }^{(25)}$ and was compared against normal-weight children (BMl-for-age value $\geq-2$ and $\leq+1 Z$-score).

IReference categories for each health-risk behaviour were: (i) having breakfast every day; (ii) eating fruit every day; (iii) eating vegetables (excluding potatoes) every day; (iv) drinking soft drinks containing sugar $\leq 3 \mathrm{~d} /$ week; (v) eating foods like potato chips (crisps), corn chips, popcorn or peanuts $\leq 3 \mathrm{~d} /$ week; (vi) eating foods like candy bars or chocolate $\leq 3 \mathrm{~d} /$ week; (vii) eating foods like biscuits, cakes, doughnuts or pies $\leq 3 \mathrm{~d} /$ week; (viii) eating foods like pizza, French fries (chips), hamburgers, sausages or meat pies $\leq 3 \mathrm{~d} /$ week; (ix) using active transportation going to and from school; ( $\mathrm{x}$ ) going to a sports or dancing club $\geq 2 \mathrm{~d} /$ week; (xi) playing outside $\geq 1$ $\mathrm{h} / \mathrm{d}$, (Xii) spending screen time $<2 \mathrm{~h} / \mathrm{d}$, and (xiil) sleep duration $\geq 9 \mathrm{~h} / \mathrm{d}$.

ICombination of 'fresh fruit' and ' $100 \%$ fruit juice'. 
Table 6 Multivariable associations $\ddagger$ between thirteen health-risk behaviours and obesity in a subgroup of children without missing data§, by country: nationally representative samples of $6-9$ year-olds, WHO European Childhood Obesity Surveillance Initiative, school year 2007/2008

\begin{tabular}{|c|c|c|c|c|c|c|c|c|c|c|c|c|}
\hline \multirow[b]{2}{*}{ Health-risk behaviour } & \multicolumn{2}{|c|}{ Bulgaria $(n 1914)$} & \multicolumn{2}{|c|}{ Czech Republic ( $n$ 936) } & \multicolumn{2}{|c|}{ Lithuania ( $n$ 2369) } & \multicolumn{2}{|c|}{ Portugal ( $n$ 1371) } & \multicolumn{2}{|c|}{ Sweden (n 1922) } & \multicolumn{2}{|c|}{$\begin{array}{l}\text { Total five countries } \\
\quad(n \text { 8512) }\end{array}$} \\
\hline & OR & $95 \% \mathrm{Cl}$ & OR & $95 \% \mathrm{Cl}$ & OR & $95 \% \mathrm{Cl}$ & OR & $95 \% \mathrm{Cl}$ & OR & $95 \% \mathrm{Cl}$ & OR & $95 \% \mathrm{Cl}$ \\
\hline \multicolumn{13}{|l|}{ Breakfast and food consumption frequency } \\
\hline 1.II Having breakfast $<7 \mathrm{~d} /$ week & $1.70^{\star \star \star}$ & $1 \cdot 26,2 \cdot 30$ & $1.91^{*}$ & $1 \cdot 14,3 \cdot 21$ & $1.80^{\star \star \star}$ & $1 \cdot 36,2 \cdot 38$ & $1.88^{*}$ & $1.02,3.46$ & $2 \cdot 20^{*}$ & $1 \cdot 12,4.33$ & $1 \cdot 81^{\star \star \star}$ & $1.52,2.15$ \\
\hline 2.II Eating fruit $\|<\mathrm{d} /$ week & 0.78 & $0.59,1.03$ & 0.99 & $0.59,1.66$ & $0.72^{\star}$ & $0.54,0.96$ & 0.82 & $0.61,1.11$ & 0.88 & $0.58,1.33$ & $0.80^{\star \star}$ & $0.69,0.93$ \\
\hline 3.II Eating vegetables (excluding potatoes) $<7 \mathrm{~d} /$ week & 0.83 & $0.60,1 \cdot 14$ & 1.31 & $0.71,2.43$ & 1.06 & $0.74,1.50$ & 1.01 & $0.74,1.36$ & $1 \cdot 14$ & $0.78,1.68$ & 1.03 & $0.88,1 \cdot 21$ \\
\hline 4.II Drinking soft drinks containing sugar $>3 \mathrm{~d} /$ week & 1.04 & $0.78,1.39$ & 0.78 & $0.48,1.28$ & $1 \cdot 17$ & $0.82,1.69$ & 1.35 & $0.94,1.93$ & 1.50 & $0 \cdot 85,2.66$ & 1.09 & $0.92,1.30$ \\
\hline $\begin{array}{l}\text { 5.II Eating foods like potato chips (crisps), corn chips, } \\
\text { popcorn or peanuts }>3 \mathrm{~d} / \text { week }\end{array}$ & $0.66^{\star \star}$ & $0.49,0.89$ & 1.23 & $0.36,4.21$ & $0.52^{*}$ & $0.27,0.98$ & $1 \cdot 71$ & $0.75,3.91$ & & - & $0.66^{\star \star \star}$ & $0.52,0.85$ \\
\hline 6.II Eating foods like candy bars or chocolate $>3 \mathrm{~d} /$ week & $1 \cdot 10$ & $0.83,1.47$ & 0.68 & $0.36,1.28$ & 0.85 & $0.63,1.14$ & 0.59 & $0.33,1.04$ & & - & 0.89 & $0.74,1.06$ \\
\hline $\begin{array}{l}\text { 7.II Eating foods like biscuits, cakes, doughnuts or } \\
\text { pies }>3 \mathrm{~d} / \text { week }\end{array}$ & $0.69^{\star}$ & $0.51,0.94$ & 0.69 & $0.36,1.31$ & 0.73 & $0.53,1.02$ & 0.79 & $0.56,1.14$ & 0.73 & $0.34,1.57$ & $0.74^{\star \star \star}$ & $0.62,0.88$ \\
\hline $\begin{array}{l}\text { 8.l Eating foods like pizza, French fries (chips), } \\
\text { hamburgers, sausages or meat pies }>3 \mathrm{~d} / \text { week }\end{array}$ & $1 \cdot 23$ & $0.90,1.68$ & $2 \cdot 24$ & $0.56,8.89$ & $1.89^{\star}$ & $1.09,3.31$ & 1.02 & $0.45,2 \cdot 27$ & 1.53 & $0.52,4.48$ & $1 \cdot 32^{*}$ & $1.04,1.69$ \\
\hline \multicolumn{13}{|l|}{ Physical activity } \\
\hline 9.II Using inactive transportation going to and from school & $1 \cdot 11$ & $0.82,1.49$ & 0.71 & $0.42,1 \cdot 20$ & $1 \cdot 16$ & $0.86,1.58$ & 1.01 & $0.71,1.43$ & 1.32 & $0.89,1.96$ & $1 \cdot 12$ & $0.96,1.30$ \\
\hline 10.II Going to a sports or dancing club $<2 \mathrm{~d} /$ week & 0.98 & $0.72,1.33$ & 0.88 & $0.53,1.47$ & 1.29 & $0.95,1.76$ & $1 \cdot 16$ & $0.84,1.60$ & 1.02 & $0.70,1.49$ & 1.07 & $0.92,1.25$ \\
\hline 11. II Playing outside $<1 \mathrm{~h} / \mathrm{d}$ & 1.37 & $0.80,2.37$ & 0.63 & $0 \cdot 19,2 \cdot 16$ & $1.59^{\star}$ & $1.03,2.45$ & 1.02 & $0.76,1.37$ & 1.28 & $0.64,2.59$ & $1 \cdot 18$ & $0.95,1.45$ \\
\hline \multicolumn{13}{|l|}{ Screen time and sleep duration } \\
\hline 12.॥ Spending screen time $\geq 2 \mathrm{~h} / \mathrm{d}$ & 1.26 & $0.94,1.69$ & $1.71^{*}$ & $1.04,2.80$ & $1.81^{\star \star *}$ & $1.27,2.59$ & 1.30 & $0.96,1.75$ & $1.83^{\star \star \star}$ & $1.26,2.65$ & $1.55^{\star \star \star}$ & $1.33,1.81$ \\
\hline 13.I Sleep duration $<9 \mathrm{~h} / \mathrm{d}$ & $1 \cdot 16$ & $0.84,1.59$ & 0.77 & $0 \cdot 26,2 \cdot 25$ & 0.87 & $0.56,1.33$ & 0.96 & $0.63,1.46$ & $2 \cdot 17$ & $0.98,4.78$ & 1.07 & $0.87,1.31$ \\
\hline
\end{tabular}

-, no observations for obese children and thus this characteristic was excluded from the Swedish multivariable analyses.

Significance levels: ${ }^{\star} P<0.05,{ }^{\star \star} P \leq 0.01,{ }^{\star \star \star} P \leq 0.001$; significant associations are shown in bold font.

†All multivariable analyses were adjusted for the children's sex and age, included all thirteen health-risk behaviours simultaneously (except in the Swedish analyses), as well as children's residential urbanization grade, parental education and parental occupation and included random effects for the primary sampling units. The analyses for the five countries together also included random effects for country.

$\S$ Normal-weight or obese children with complete information on sex, whose age was between 6 and 9 years old, whose weight and height were measured, whose BMI-for-age $Z$-score was within the normal range ( $\geq-5$ and $\leq+5$ ), who returned a filled out family record form and who had no missing values on any of the thirteen health-risk behaviours, children's residential urbanization grade, parental education and parental occupation. Obesity is defined as the proportion of children with a BMI-for-age value $>+2$ Z-score (i.e. BMI-for-age above +2 sD relative to the median BMI-for-age of the 2007 WHO growth reference) ${ }^{(25)}$ and was compared against normal-weight children (BMI-for-age value $\geq-2$ and $\leq+1$ Z-score).

IIReference categories for each health-risk behaviour were: (i) having breakfast every day; (ii) eating fruit every day; (iii) eating vegetables (excluding potatoes) every day; (iv) drinking soft drinks containing sugar $\leq 3 \mathrm{~d} /$ week; (v) eating foods like potato chips (crisps), corn chips, popcorn or peanuts $\leq 3 \mathrm{~d} /$ week; (vi) eating foods like candy bars or chocolate $\leq 3 \mathrm{~d} /$ week; (vii) eating foods like biscuits, cakes, doughnuts or pies $\leq 3 \mathrm{~d} /$ week; (viii) eating foods like pizza, French fries (chips), hamburgers, sausages or meat pies $\leq 3 \mathrm{~d} / \mathrm{week}$; (ix) using active transportation going to and from school; ( $\mathrm{x}$ ) going to a sports or dancing club $\geq 2 \mathrm{~d} / \mathrm{week}$; (xi) playing outside $\geq 1$ $\mathrm{h} / \mathrm{d}$; (xii) spending screen time $<2 \mathrm{~h} / \mathrm{d}$; and (xiii) sleep duration $\geq 9 \mathrm{~h} / \mathrm{d}$.

TCombination of 'fresh fruit' and ' $100 \%$ fruit juice'. 
Table 7 Associationsł between three risk behaviour scores and obesity in a subgroup of children without missing data§, by country: nationally representative samples of 6-9-year-olds, WHO European Childhood Obesity Surveillance Initiative, school year 2007/2008

\begin{tabular}{|c|c|c|c|c|c|c|c|c|c|c|c|c|c|c|c|c|c|c|}
\hline \multirow[b]{2}{*}{ Score category } & \multicolumn{3}{|c|}{ Bulgaria } & \multicolumn{3}{|c|}{ Czech Republic } & \multicolumn{3}{|c|}{ Lithuania } & \multicolumn{3}{|c|}{ Portugal } & \multicolumn{3}{|c|}{ Sweden } & \multicolumn{3}{|c|}{ Total five countries } \\
\hline & $n$ & OR & $95 \% \mathrm{Cl}$ & $n$ & OR & $95 \% \mathrm{Cl}$ & $n$ & OR & $95 \% \mathrm{Cl}$ & $n$ & OR & $95 \% \mathrm{Cl}$ & $n$ & OR & $95 \% \mathrm{Cl}$ & $n$ & OR & $95 \% \mathrm{Cl}$ \\
\hline \multicolumn{19}{|c|}{ Food-risk behaviour score } \\
\hline 0 & 52 & & 1.00 & 64 & & 1.00 & 85 & & 1.00 & 248 & & 1.00 & 756 & & 1.00 & 1205 & & 1.00 \\
\hline 1 & 114 & 0.80 & $0.34,1.86$ & 178 & 0.75 & $0.27,2.07$ & 292 & 0.93 & $0.43,2.00$ & 449 & 0.99 & $0.66,1.50$ & 620 & $1 \cdot 75^{*}$ & $1 \cdot 13,2.72$ & 1653 & 1.20 & $0.93,1.55$ \\
\hline 2 & 288 & 0.87 & $0.41,1.83$ & 270 & 0.93 & $0.36,2.40$ & 683 & 0.81 & $0.40,1.67$ & 407 & 1.05 & $0.69,1.60$ & 399 & 1.61 & $0.98,2.63$ & 2047 & 1.21 & $0.93,1.56$ \\
\hline 3 & 359 & 0.92 & $0.44,1.92$ & 231 & 0.69 & $0.26,1.87$ & 671 & 1.05 & $0.52,2.15$ & 155 & $1 \cdot 10$ & $0.65,1.85$ & 106 & 1.68 & $0.79,3.56$ & 1522 & 1.28 & $0.97,1.69$ \\
\hline 4 & 356 & 0.68 & $0.32,1.44$ & 128 & 0.72 & $0.25,2.14$ & 350 & 0.78 & $0.36,1.68$ & 68 & 0.82 & $0.39,1.71$ & 28 & 1.45 & $0.32,6.50$ & 930 & 0.98 & $0.72,1.35$ \\
\hline 5 & 355 & 0.81 & $0.38,1.70$ & 45 & 0.70 & $0.18,2.75$ & 197 & 0.93 & $0.41,2 \cdot 12$ & 27 & 0.76 & $0.25,2.33$ & 6 & & - & 630 & $1 \cdot 10$ & $0.78,1.55$ \\
\hline 6 & 253 & 0.65 & $0.30,1.44$ & 15 & $2 \cdot 21$ & $0.47,10.53$ & 69 & 1.41 & $0.55,3.63$ & 14 & $1 \cdot 18$ & $0.31,4.51$ & 4 & & - & 355 & 1.04 & $0.70,1.56$ \\
\hline 7 & 117 & 0.61 & $0.25,1.48$ & 4 & 2.07 & $0.16,27 \cdot 49$ & 22 & 0.33 & $0.04,2.76$ & 3 & 2.00 & $0.17,23.69$ & 2 & & - & 148 & 0.80 & $0.45,1.43$ \\
\hline 8 & 20 & 0.46 & $0.09,2.38$ & 1 & & - & 0 & & - & 0 & & - & 1 & & - & 22 & 0.95 & $0.27,3.39$ \\
\hline \multicolumn{19}{|c|}{ Physical activity-risk behaviour score } \\
\hline 0 & 70 & & 1.00 & 130 & & 1.00 & 102 & & $1.00 \dagger$ & 44 & & 1.00 & 351 & & $1.00 \dagger \dagger$ & 697 & & $1.00 \dagger \dagger$ \\
\hline 1 & 411 & 0.70 & $0.36,1.36$ & 394 & 1.07 & $0.49,2.34$ & 553 & 1.74 & $0.67,4.53$ & 304 & 0.67 & $0.31,1.45$ & 742 & 1.79 & $0.90,3.54$ & 2404 & 1.21 & $0.87,1.67$ \\
\hline 2 & 948 & 0.77 & $0.41,1.45$ & 306 & 1.67 & $0.77,3.63$ & 1009 & 2.39 & $0.94,6.05$ & 516 & 0.62 & $0.29,1.31$ & 606 & $2 \cdot 75^{\star \star}$ & $1.40,5.41$ & 3385 & $1.47^{*}$ & $1.07,2.03$ \\
\hline 3 & 414 & 0.98 & $0.51,1.88$ & 92 & 0.98 & $0.35,2 \cdot 78$ & 615 & $3.02^{*}$ & $1 \cdot 18,7 \cdot 74$ & 370 & 0.82 & $0.38,1.76$ & 206 & $3 \cdot 03^{\star \star}$ & $1.40,6.57$ & 1697 & $1 \cdot 79^{\star \star \star}$ & $1.28,2.50$ \\
\hline 4 & 64 & 1.05 & $0.44,2.49$ & 14 & & - & 79 & $2 \cdot 17$ & $0.67,7.01$ & 125 & 0.95 & $0.41,2.18$ & 17 & $7 \cdot 19^{\star \star}$ & $1.72,30.02$ & 299 & $1 \cdot 83^{\star \star}$ & $1.19,2.84$ \\
\hline 5 & 7 & & - & 0 & & - & 11 & $4 \cdot 30$ & $0.70,26.29$ & 12 & 0.56 & $0.10,3.05$ & 0 & & - & 30 & 1.26 & $0.41,3.85$ \\
\hline \multicolumn{19}{|c|}{ Health-risk behaviour scorell } \\
\hline $0-1$ & 31 & & 1.00 & 66 & & 1.00 & 46 & & 1.00 & 103 & & 1.00 & 565 & & $1.00 \dagger \dagger$ & 811 & & 1.00 \\
\hline 2 & 81 & 0.88 & $0.30,2.59$ & 136 & 0.62 & $0.20,1.89$ & 163 & 1.32 & $0.36,4.84$ & 205 & 0.86 & $0.45,1.66$ & 510 & $1 \cdot 16$ & $0.65,2.08$ & 1095 & 1.11 & $0.78,1.58$ \\
\hline 3 & 138 & 1.04 & $0.38,2.84$ & 215 & 0.82 & $0 \cdot 30,2 \cdot 22$ & 338 & $1 \cdot 75$ & $0.51,5.98$ & 320 & 1.05 & $0.58,1.92$ & 464 & $2 \cdot 34^{\star \star}$ & $1.38,3.96$ & 1475 & $1 \cdot 64^{\star \star}$ & $1 \cdot 18,2 \cdot 27$ \\
\hline 4 & 247 & 0.84 & $0.32,2.21$ & 208 & $1 \cdot 14$ & $0.43,3.00$ & 502 & 1.49 & $0.44,5.05$ & 309 & 1.23 & $0.68,2.23$ & 238 & $2 \cdot 66^{\star \star \star}$ & $1.47,4.81$ & 1504 & $1 \cdot 64^{\star \star}$ & $1.17,2.29$ \\
\hline 5 & 316 & 1.00 & $0.39,2.61$ & 153 & 0.89 & $0.32,2.52$ & 509 & 1.97 & $0.59,6.63$ & 219 & 1.13 & $0.60,2 \cdot 11$ & 98 & 1.26 & $0.49,3.23$ & 1295 & $1 \cdot 68^{\star \star}$ & $1 \cdot 19,2.37$ \\
\hline 6 & 297 & 0.70 & $0.26,1.85$ & 97 & 0.62 & $0.19,2.02$ & 419 & 1.65 & $0.49,5.62$ & 107 & 1.66 & $0.83,3.33$ & 33 & $3 \cdot 69^{\star}$ & $1.26,10.82$ & 953 & $1.50^{*}$ & $1.04,2.16$ \\
\hline 7 & 342 & 0.75 & $0.29,1.97$ & 35 & 1.42 & $0.38,5 \cdot 29$ & 232 & 1.99 & $0.57,6.93$ & 72 & 0.98 & $0.44,2.19$ & 8 & 3.58 & $0.40,31.65$ & 689 & $1 \cdot 48^{*}$ & $1.01,2.18$ \\
\hline 8 & 263 & 0.98 & $0.37,2.59$ & 18 & 0.64 & $0.07,5.88$ & 115 & 1.82 & $0.49,6.82$ & 23 & 0.73 & $0.19,2.75$ & 4 & & - & 423 & $1.57^{*}$ & $1.03,2.41$ \\
\hline 9 & 144 & 0.58 & $0.20,1.68$ & 5 & 1.64 & $0.14,18.83$ & 32 & 3.47 & $0.78,15.46$ & 10 & & - & 1 & & - & 192 & $1 \cdot 13$ & $0.64,1.97$ \\
\hline 10 & 48 & 1.08 & $0.33,3.52$ & 2 & & - & 10 & & - & 2 & & - & 1 & & - & 63 & 1.40 & $0.64,3.10$ \\
\hline 11 & 6 & 0.72 & $0.07,7.67$ & 1 & & - & 3 & & - & 1 & & - & 0 & & - & 11 & $7 \cdot 10^{\star \star}$ & $2.00,25.20$ \\
\hline 12 & 1 & & - & 0 & & - & 0 & & - & 0 & & - & 0 & & - & 1 & & - \\
\hline 13 & 0 & & - & 0 & & - & 0 & & - & 0 & & - & 0 & & - & 0 & & - \\
\hline
\end{tabular}

-, sample size was 0 or none of the children in this score category were obese and thus the OR could not be estimated for this category.

Significance levels of OR: ${ }^{*} P<0.05,{ }^{* *} P \leq 0.01,{ }^{* * \star} P \leq 0.001$; significant associations are shown in bold font.

Significant linear trend of $\mathrm{OR}$ for the respective risk-behaviour score (likelihood ratio test): $\dagger P<0.01,+\dagger P<0.001$

$\ddagger$ All analyses were adjusted for the children's sex and age, children's residential urbanization grade, parental education and parental occupation and included random effects for the primary sampling units. The analyses for the five countries together also included random effects for country.

$\S$ Normal-weight or obese children with complete information on sex, whose age was between 6 and 9 years old, whose weight and height were measured, whose BMI-for-age Z-score was within the normal range $(\geq-5$ and $\leq+5$ ), who returned a filled out family record form and who had no missing values on any of the thirteen health-risk behaviours, children's residential urbanization grade, parental education and parental occupation. Obesity is defined as the proportion of children with a BMI-for-age value $>+2$ Z-score (i.e. BMI-for-age above +2 sD relative to the median BMI-for-age of the 2007 WHO growth reference) ${ }^{(25)}$ and was compared against normal-weight children (BMl-for-age value $\geq-2$ and $\leq+1 Z$-score).

IIThe reference category was not set as a health risk score of 0 but $0-1$, because only six Bulgarian, fifteen Czech, seven Lithuanian, nine Portuguese and 160 Swedish children obtained a health risk score of 0 . 
risk-behaviour scores and overweight. Same as with obesity (Table 7), none of the food-risk behaviour scores were associated with overweight. The presence of two to four physical activity-related risk behaviours was clearly associated with higher odds of overweight, whereas the combination of four food- and physical activity-related risk behaviours only was positively associated with overweight.

\section{Discussion}

We assessed the prevalence of thirteen health-risk behaviours related to food consumption frequencies and physical activity among primary-school children in five European countries and examined their association, both individually and combined, with obesity and overweight. The highest prevalence of many risk behaviours was observed in Bulgaria and the lowest in Sweden, whereas the other three countries did not show a clear country order ranking pattern across the behaviours. For instance, Portugal was ranked just before Sweden for the foodrelated but not for the physical activity-related risk behaviours. Bulgarian and Portuguese children were more obese than Czech, Lithuanian and Swedish children. The statistically significant associations found between the food-related risk behaviours and obesity showed contrasting results although they were consistent across the countries, whereas the significant associations between physical activity-related risk behaviours and obesity were all positive. Moreover, the three calculated risk behaviour scores were positively associated with obesity, most pronounced in Swedish children or in the group of children in the five countries.

To our knowledge, nationally representative Europeanwide studies collecting data on behaviours related to both nutrition and/or physical activity, as well as using a common data collection protocol, are scarce. Two studies, both targeting adolescents, could be identified: the HBSC targeting 11-, 13- and 15-year-olds ${ }^{(16)}$ and the 'European energy balance research to prevent excessive weight gain among youth (ENERGY)' project targeting 10-12year-olds $^{(28)}$. We could compare our results with those for one behaviour only in each of these two studies. The other behavioural indicators that were given in their reports were defined differently or presented in another way. Comparing with the results from the 11-year-olds in the HBSC survey from $2005 / 2006^{(16)}$, slight differences in the risk behaviour 'eating fruit $<7 \mathrm{~d}$ /week' are seen in HBSC (Portugal, 48\%; Bulgaria, 52\%; Czech Republic, 57\%, Sweden, 59\%; Lithuania, 72\%), whereby Bulgaria was grouped in the more favourable and Sweden in the less favourable country group, which is opposite to our data $(\text { Table } 3)^{(16)}$. The percentage of children in COSI who did not have breakfast every day (range 4-33\%) was on average lower than the percentage found in 10-12-year-old adolescents in the seven European countries participating in the ENERGY project (boys, 17-52\%; girls, 12-51\%) ${ }^{(28)}$. This difference may be due to the younger age of the COSI children as it has been suggested elsewhere that skipping breakfast is more prevalent among older children $^{(29)}$.

Other identified European-wide studies included sub-nationally representative samples of children ${ }^{(30,31)}$ or adolescents $^{(32)}$ or secondary data sets based on different measures ${ }^{(33)}$. Therefore comparisons of their data with ours are difficult.

We assessed the average number of less favourable behaviours present by assigning a risk score to each child. We could identify two Dutch studies that also summarized the number of behaviours children were engaged in by means of a risk score ${ }^{(34,35)}$. However, comparisons with their results were not possible because of the use of different and fewer behavioural indicators.

None of the six abovementioned European-wide studies $^{(16,28,30-33)}$ that have collected data on individual behaviours related to both nutrition and/or physical activity used the score approach. Instead, three ${ }^{(36-38)}$ have performed cluster analysis to study interrelationships among multiple behaviours and to identify high-risk groups of children in Europe, whereby country representation varied in the different clusters ${ }^{(36)}$ and not necessarily all less favourable behaviours occurred simultaneously in a cluster ${ }^{(36-38)}$. This has also been shown in country-specific studies that used similar foodrelated and/or physical activity-related behaviours ${ }^{(39-41)}$. COSI has been set up to monitor data by country and to make intercountry comparisons possible. We did not consider the available number of children with complete data on the thirteen risk behaviours sufficient to find a reasonable amount of differentiable clusters by country that would be large enough to warrant strategic attention $^{(42)}$.

It is expected that children with excess body weight are more likely to be engaged in less favourable behaviours. This was the case in our study for two food-related risk behaviours: not having breakfast every day and eating 'foods like pizza, French fries (chips), hamburgers, sausages or meat pies' $>3 \mathrm{~d} /$ week (Table 6). But we also found the opposite to be true for three food-related risk behaviours of not eating fruit every day, eating 'foods like potato chips (crisps), corn chips, popcorn or peanuts' $>3$ $\mathrm{d}$ /week and eating 'foods like biscuits, cakes, doughnuts or pies' $>3$ d/week (Table 6), whereby children performing these three behaviours were less likely to be obese or overweight (Supplementary Table 5). A possible explanation for these results may be the cross-sectional nature of the COSI data and thus reverse causality has to be taken into account. Children with excess body weight may already have changed their eating patterns and therefore have truthfully answered the form according to the current situation and not according to what actually may have led to their overweight status. 
Positive associations between skipping breakfast and excess weight have been also been reported by several other studies $^{(34,43,44)}$, while to our knowledge a negative association between low fruit intake and obesity or overweight in just a few ${ }^{(33)}$. We did not find relevant studies to compare with for the other two less favourable foodrelated behaviours (items (v) and (vii)) for which we found statistically significant negative associations with obesity and overweight, and the second less favourable food-related behaviour (item (viii)) for which we found a statistically significant positive association with obesity. Concerning the five physical-activity related risk behaviours in our study, spending screen time $\geq 2 \mathrm{~h} / \mathrm{d}$ and playing outside $<1 \mathrm{~h} / \mathrm{d}$ were the only behaviours that were statistically significantly associated with higher odds of obesity. Positive associations between watching television and other screen activities and BMI have also been reported by several other studies ${ }^{(33,34,45)}$.

It has been suggested that a combination of less favourable behaviours related to both nutrition and physical activity may have a possible synergetic effect that could lead to a multiplication of the risk of obesity or overweight $^{(34,36,38-40)}$. In our study, we found for the total group of children in the five countries that a health-risk behaviour score of 3-8 or a score of 11 (thus a combination of three or more less favourable behaviours on both nutrition and physical activity), as well as a physical activity-risk behaviour score of 2-4, led to higher odds of obesity (Table 7). This was not shown for the food-risk behaviour score.

Several methodological issues of the present study need to be acknowledged. Its strengths include the availability of nationally representative samples of more than 10000 children, the administration of the same COSI family form in five countries, which enabled the intercountry comparisons, as well as the standardized weight and height measurements ${ }^{(12)}$. However, the study also has some limitations.

The first set of concerns relates to the questionnaire used. For instance, the questions on the children's behaviours were adapted from the HBSC 2002 questionnaire ${ }^{(15)}$ that has been validated among adolescents ${ }^{(46)}$, but to our knowledge not among children within the COSI targeted age range of 6-9 years. Furthermore, in the COSI questions we used fewer answer categories than incorporated in the HBSC questionnaire, because the COSI family form was designed to give a rough indication of the prevalence of the children's health-risk behaviours and not for detailed analyses between risk behaviours and health outcomes. For instance, the COSI FFQ uses four frequency categories for a usual week while the 2001/2002 HBSC uses seven ${ }^{(15)}$. In our questionnaire, we also did not collect data on portion sizes, which have been suggested to be positively associated with obesity ${ }^{(47)}$.

A second set of concerns relates to filling in the questionnaire. For example, the data were reported by the parents (possibly together with their child). COSI was introduced to the parents as a European Childhood Growth Study with the aim to promote the health and well-being among primary-school children, the words overweight or obesity were not mentioned, and the children's height and weight measurement values were only provided to the parents upon request. Nevertheless, it might be that parents were aware of their child's weight status and that this could have influenced the report on their child's behaviours. Parents with overweight children are likely to over-report more favourable behaviours and under-report less favourable behaviours ${ }^{(48,49)}$, and parents who are concerned about their child's weight status are more likely to limit child screen time, take steps to improve their child's diet or increase their child's physical activity ${ }^{(50)}$. In addition, we do not know to what extent the parents completed the form solely by themselves or together with their child. A validation study comparing the children's report with their parent's report on the children's energy intake using FFQ suggests that children (aged 8-11 years) are more accurate reporters than their parents, and that fathers are more accurate than mothers ${ }^{(51)}$.

A third concern relates to the representativeness of the children in our analysis. One-third of the children included in the analysis had a missing value on any of the healthrisk behaviours or on children's residential urbanization grade, parental education or parental occupation. Compared with the group of children with missing values ( $n$ 5126), the subgroup of children without any missing values ( $n$ 10 517) included $14.2 \%$ fewer children whose parents had a low educational level, $2 \cdot 3 \%$ fewer children whose parents were both unemployed and 5.6\% more children who lived in the urban area. In addition, the subgroup contained fewer children for five less favourable behaviours (range absolute difference: -1 to $-8 \%$ ) and more children for four less favourable behaviours (range absolute difference: +2 to $+4 \%$ ). While these statistically significant, although relatively small, group differences may have influenced the results of the multivariable analyses, it is likely that the missing data were at random and that the effect estimates were not biased ${ }^{(52)}$.

A final limitation relates to the fact that only five out of thirteen countries administered the voluntary family form in COSI round 2007/2008. This allows us to make some intercountry comparisons, but obviously the number of countries is too small to identify groups of countries with similar patterns of health-risk behaviours like we could do with the data on the children's weight and height measurements ${ }^{(14)}$ and with the data on the school nutrition environment ${ }^{(53)}$.

\section{Conclusion}

In conclusion, despite a categorization of behaviours that was based on international health recommendations, only four out of thirteen health-risk behaviours were found to 
be positively associated with obesity and three were even found to be negatively associated with obesity or overweight. A combination of health-risk behaviours, on the other hand, showed more consistent findings and all in the same direction. The significant positive associations found between the physical activity-risk scores and obesity, as well as between the health-risk scores and obesity, underline the importance of, in particular, promoting physical activity-related and discouraging sedentary behaviours among schoolchildren in the context of obesity preventive interventions.

Given the strengths and limitations, the data collected in the present study can be considered valuable at the country level to indicate the level of behavioural health risks on nutrition and physical activity among primaryschool children. The results show that with the present data it is possible to investigate variations in behaviours across countries, but to identify sub-European differences in behavioural health risks among schoolchildren, data from more countries should be collected. COSI includes repeated data collection rounds in 2-3-year intervals, whereby with each round more countries are expected to join $^{(12)}$. It is thus envisaged that future rounds may provide more explanatory suggestions for the overweight northsouth gradient found in other COSI analyses, whereby the highest prevalence was found in southern European countries $^{(14,54)}$.

\section{Acknowledgements}

Acknowledgements: Sincere appreciation is expressed to Francesco Mitis and Casimiro Canha Cavaco Dias of the WHO Regional Office for Europe for critically reviewing the final draft of this paper. The authors would also like to thank sincerely Richelle Vlenterie, former intern at the WHO Regional Office for Europe, who performed a literature search for this paper and assisted with the preliminary analysis. Financial support: Data collection in the countries was made possible through funding by the following bodies. In Bulgaria: Ministry of Health, the National Center of Public Health and Analyses (the former National Center of Public Health Protection) and Regional Health Inspectorates; in Czech Republic: Internal Grant Agency of the Ministry of Health (grant number IGA NT/ 13735-4); in Lithuania: Lithuanian State Science and Studies Foundation, Lithuanian University of Health Sciences (the former Kaunas University of Medicine) and the Research Council of Lithuania (grant number SIN-17/ 2012); in Portugal: Ministry of Health and Regional Health Directorates; in Sweden: Swedish Research Council for Health, Working Life and Welfare and the Swedish Research Council. The authors gratefully acknowledge the Directorate-General for Health of Portugal, the National Health Institute Doutor Ricardo Jorge in Lisbon, Portugal; the National Institute of Health in Rome, Italy; the
Norwegian Institute of Public Health in Oslo, Norway; the Hellenic Medical Association for Obesity in Athens, Greece; the Directorate-General for Health of France; and the Karolinska Institute in Huddinge, Sweden for their financial support for the organization of COSI meetings where the data collection procedures and analyses were discussed. Conflict of interest: The authors declare no conflict of interest. Disclaimer: T.M.A.W. and J.B. are staff members of the WHO Regional Office for Europe. The authors alone are responsible for the views expressed in this publication and they do not necessarily represent the decisions or the stated policy of the World Health Organization. Authorship: T.M.A.W. conceptualized and drafted the manuscript and conducted all analyses; J.M.A.v.R. made substantial contributions to the conception and drafts of the manuscript, as well as interpretation of the results; A.Y., A.S. and M.K. were involved in critically reviewing a draft of the manuscript and contributed with data collection and data cleaning; V.D. A.P., A.I.R. and J.B. contributed with data collection and data cleaning. All authors contributed to and approved the final manuscript. Ethics of human subject participation: This study was conducted according to the guidelines laid down in the Declaration of Helsinki and all procedures involving human subjects were approved by local ethical committees. Parents were fully informed about the anthropometric measurements, and their written informed consent was obtained using either an active or passive approach. Children's consent was always obtained prior to the measurements, and confidentiality of all collected and archived data was ensured. In Bulgaria ethics approval had to be sought from the Medical Ethical Committee of the former National Center of Public Health Protection and permission to be granted before the start of the survey. The documents that needed to be sent to the Committee were: the application request, the study design and protocol with questionnaires, the list of participants and the parent's informed consent letter (passive approach). Further, three levels of permission had to be asked for the conduct of the study: firstly for the access to the schools from the Ministry of Education, then this permission letter and further information were provided to the Regional Inspectorates of Education, and thirdly the administration (director) of each school had to be asked for approval. A teacher was not permitted to participate if a director had not agreed. In the Czech Republic the study was agreed by the Institutional Ethical Committee of the Institute of Endocrinology in Prague after having received the detailed design of the study in 2008. The approval letter is archived in the Ethical Committee of the Institute of Endocrinology. Paediatricians who perform the obligatory 7-year preventive check-up at paediatric clinics informed parents about the study and the measuring procedures, and gave them an informed consent form to sign before their child was measured for the study. Children were also asked to express their agreement to participate in the study before 
being included. Ethics approval for the 'Growth surveillance study of Lithuanian children' was sought in January 2008 from the Lithuanian Bioethics Committee. Permission was granted in March 2008. The documents that needed to be sent to the Committee as part of the ethics approval procedures were: the application requesting permission to perform the biomedical survey, a filled out application form for biomedical research, the study protocol, questionnaires and information on the confidentiality of personal information, a filled out ethical evaluation form for biomedical research, the curriculum vitae of the applicant and the applicant's criminal history. In addition, approval to implement the study in schools was sought from the Lithuanian Ministry of Education and Science and the education departments in local municipalities. In Portugal, the Directorate-General for Health in Lisbon sought ethics approval from the Portuguese Data Protection Authority. All methodological aspects, particularly the anthropometric measurements of the children and a precise explanation of the informed parental consent and children's consent on the day of the measurements, were included in the application. The approval letter was sent to the Directorate-General for Health and archived there. In Sweden, ethics approval was sought in 2008 from the Regional Ethics Committee in Gothenburg for data collection in the southern and western parts of Sweden and from the Regional Ethics Committee in Stockholm for data collection in the northern and eastern parts of Sweden. The procedures to follow were exactly the same for both regional committees and one form about the procedures was completed at each site. This included a full description of the project, a research plan including research questions to be answered, all details about the measurements to be made, the data collection procedures and secure data handling. It also included letters informing parents and teachers about the project, parental consent and information to children. Questions regarding possible risk/benefit to the children were answered as well as how the data would be coded on individual level and handled according to Swedish law. Approval from the Stockholm committee was granted while the Gothenburg committee stated that no approval was needed.

\section{Supplementary material}

To view supplementary material for this article, please visit http://dx.doi.org/10.1017/S1368980015001937

\section{References}

1. World Health Organization (2012) Population-Based Approaches to Childhood Obesity Prevention. Geneva: WHO; available at http://apps.who.int/iris/bitstream/ 10665/80149/1/9789241504782_eng.pdf

2. Branca F, Nikogosian H \& Lobstein T (editors) (2007) The Challenge of Obesity in the WHO European Region and the
Strategies for Response. Copenhagen: WHO Regional Office for Europe; available at http://www.euro.who.int/_data/ assets/pdf_file/0010/74746/E90711.pdf

3. de Onis M, Blössner M \& Borghi E (2010) Global prevalence and trends of overweight and obesity among preschool children. Am J Clin Nutr 92, 1257-1264.

4. Muthuri SK, Francis CE, Wachira LJ et al. (2014) Evidence of an overweight/obesity transition among school-aged children and youth in Sub-Saharan Africa: a systematic review. PLoS One 9, e92846.

5. Mirmiran P, Sherafat-Kazemzadeh R, Jalali-Farahani $\mathrm{S}$ et al. (2010) Childhood obesity in the Middle East: a review. East Mediterr Health J 16, 1009-1017.

6. European Commission (2014) EU Action Plan on Childhood Obesity 2014-2020. Brussels: EC.

7. World Health Organization (2014) Report of the First Meeting of the Ad hoc Working Group on Science and Evidence for Ending Childhood Obesity, 18-20 June 2014, Geneva, Switzerland. Geneva: WHO; available at http://www.who.int/ end-childhood-obesity/echo-final-report-august-2014.pdf?

8. Craigie AM, Lake AA, Kelly SA et al. (2011) Tracking of obesity-related behaviours from childhood to adulthood: a systematic review. Maturitas 70, 266-284.

9. Singh AS, Mulder C, Twisk JW et al. (2008) Tracking of childhood overweight into adulthood: a systematic review of the literature. Obes Rev 9, 474-488.

10. Wilkinson JR, Walrond S, Ells LJ et al. (2007) Surveillance and monitoring. Obes Rev 8, Suppl. 1, 23-29.

11. World Health Organization Regional Office for Europe (2006) European Charter on Counteracting Obesity. Copenhagen: WHO Regional Office for Europe; available at http://www.euro.who.int/_data/assets/pdf_file/0009/87462/ E89567.pdf

12. Wijnhoven T, van Raaij J \& Breda J (2014) WHO European Childhood Obesity Surveillance Initiative. Implementation of Round 1 (2007/2008) and Round 2 (2009/2010). Copenhagen: WHO Regional Office for Europe; available at http:// www.euro.who.int/_data/assets/pdf_file/0004/258781/COSIreport-round-1-and-2_final-for-web.pdf?

13. Wijnhoven T \& Branca F (2008) WHO European Childhood Obesity Surveillance Initiative. Protocol, version January 2008. Copenhagen: WHO Regional Office for Europe.

14. Wijnhoven TMA, van Raaij JMA, Spinelli A et al. (2013) WHO European Childhood Obesity Surveillance Initiative 2008: weight, height and body mass index in 6-9-year-old children. Pediatr Obes 8, 79-97.

15. Currie C, Samdal O, Boyce W et al. (editors) (2002) Health Behaviour in School-Aged Children: A WHO Cross-National Study. Research Protocol for the 2001/2002 Survey. Edinburgh: University of Edinburgh.

16. Currie C, Gabhainn SN, Godeau E et al. (editors) (2008) Inequalities in Young People's Health. Health Behaviour in School-Aged Children International Report from the 2005/ 2006 Survey. Copenhagen: WHO Regional Office for Europe; available at http://www.euro.who.int/_data/ assets/pdf_file/0005/53852/E91416.pdf

17. World Health Organization (2009) Global School-Based Student Health Survey. Part 12: Core Module Rationale. Geneva: WHO; available at http://www.who.int/chp/gshs/ GSHS_Item_Rationales_2009_English.pdf

18. Centers for Disease Control and Prevention (2013) Nutrition for Everyone: Fruits and Vegetables. http://www.cdc.gov/ nutrition/everyone/fruitsvegetables/index.html (accessed March 2015).

19. World Health Organization Regional Office for Europe (2006) Food and Nutrition Policy for Schools. A Tool for the Development of School Nutrition Programmes in the European Region. Copenhagen: WHO Regional Office for Europe; available at http://www.euro.who.int/_data/assets/pdf_file/ 0019/152218/E89501.pdf?ua=1 
20. World Health Organization (2010) Set of Recommendations on the Marketing of Foods and Non-Alcoholic Beverages to Children. Geneva: WHO; available at http://whqlibdoc. who.int/publications/2010/9789241500210_eng.pdf

21. World Health Organization (2010) Global Recommendations on Physical Activity for Health. Geneva: WHO; available at http://whqlibdoc.who.int/publications/2010 /9789241599979_eng.pdf?ua=1

22. American Academy of Pediatrics Committeee on Public Education (2001) Children, adolescents, and television. Pediatrics 107, 423-426.

23. World Health Organization Regional Office for Europe (2004) WHO Technical Meeting on Sleep and Health, Bonn, Germany, 22-24 January 2004. Copenhagen: WHO Regional Office for Europe; available at http://www.euro. who.int/_data/assets/pdf_file/0008/114101/E84683.pdf

24. World Health Organization (1995) Physical Status: The Use and Interpretation of Anthropometry. Report of a WHO Expert Committee. WHO Technical Report Series, no. 854. Geneva: WHO; available at http://apps.who.int/iris/ bitstream/10665/37003/1/WHO_TRS_854.pdf

25. de Onis M, Onyango AW, Borghi E et al. (2007) Development of a WHO growth reference for school-aged children and adolescents. Bull World Health Organ 85, 660-667.

26. Blössner M, Siyam A, Borghi E et al. (2009) WHO AnthroPlus for Personal Computers Manual. Software for Assessing Growth of the World's Children and Adolescents. Geneva: WHO; available at http://www.who.int/growthref/tools/ who_anthroplus_manual.pdf

27. Marascuilo LA (1966) Large-sample multiple comparison. Psychol Bull 65, 280-290.

28. Brug J, van Stralen MM, te Velde SJ et al. (2012) Differences in weight status and energy-balance related behaviours among schoolchildren across Europe: the ENERGY-project. PLoS One 7, e34742.

29. Rampersaud GC, Pereira MA, Girard BL et al. (2005) Breakfast habits, nutritional status, body weight, and academic performance in children and adolescents. $J$ Am Diet Assoc 105, 743-760.

30. Riddoch C, Edwards D, Page A et al. (2005) The European Youth Heart Study - cardiovascular disease risk factors in children: rationale, aims, study design and validation of methods. J Phys Act Health 2, 115-129.

31. Ahrens W, Bammann K, de Henauw S et al. (2006) Understanding and preventing childhood obesity and related disorders - IDEFICS: a European multilevel epidemiological approach. Nutr Metab Cardiovasc Dis 16, 302-308.

32. Moreno LA, De Henauw S, González-Gross M et al. (2008) Design and implementation of the Healthy Lifestyle in Europe by Nutrition in Adolescence Cross-Sectional Study. Int J Obes (Lond) 32, Suppl. 5, S4-S11.

33. van Stralen MM, te Velde SJ, van Nassau F et al. (2012) Weight status of European preschool children and associations with family demographics and energy balance-related behaviours: a pooled analysis of six European Studies. Obes Rev 13, Suppl. 1, 29-41.

34. Veldhuis L, Vogel I, Renders CM et al. (2012) Behavioral risk factors for overweight in early childhood; the 'Be active, eat right' study. Int J Behav Nutr Phys Act 9, 74.

35. Jansen W, Mackenbach JP, Joosten-van Zwanenburg E et al. (2010) Weight status, energy-balance behaviours and intentions in 9-12-year-old inner-city children. J Hum Nutr Diet 23, 85-96.

36. Fernández-Alvira JM, De Bourdeaudhuij I, Singh AS et al. (2013) Clustering of energy balance-related behaviors and parental education in European children: the ENERGY project. Int J Behav Nutr Phys Act 10, 5.

37. Bel-Serrat S, Mouratidou T, Santaliestra-Pasías AM et al. (2013) Clustering of multiple lifestyle behaviours and its association to cardiovascular risk factors in children: the IDEFICS study. Eur J Clin Nutr 67, 848-854.

38. Ottevaere C, Huybrechts I, Benser J et al. (2011) Clustering patterns of physical activity, sedentary and dietary behavior among European adolescents: the HELENA study. BMC Public Health 11, 328.

39. Landsberg B, Plachta-Danielzik S, Lange D et al. (2010) Clustering of lifestyle factors and assocation with overweight in adolescents of the Kiel Obesity Prevention Study. Public Health Nutr 13, 1708-1715.

40. Sabbe D, De Bourdeaudhuij I, Legiest E et al. (2008) A cluster-analytical approach towards physical activity and eating habits among 10-year-old children. Health Educ Res 23, 753-762.

41. Cameron AJ, Crawford DA, Salmon J et al. (2011) Clustering of obesity-related risk behaviors in children and their mothers. Ann Epidemiol 21, 95-102.

42. Mooi E \& Sarstedt M (2011) Cluster analysis. In A Concise Guide to Market Research: The Process, Data, and Methods Using IBM SPSS Statistics, 2nd ed., pp. 237-284 [E Mooi and M Sarstedt, editors]. Heidelberg: SpringerVerlag.

43. Horikawa C, Kodama S, Yachi Y et al. (2011) Skipping breakfast and prevalence of overweight and obesity in Asian and Pacific regions: a meta-analysis. Prev Med 53, 260-267.

44. Szajewska H \& Ruszczynski M (2010) Systematic review demonstrating that breakfast consumption influences body weight outcomes in children and adolescents in Europe. Crit Rev Food Sci Nutr 50, 113-119.

45. Olafsdottir S, Berg C, Eiben G et al. (2014) Young children's screen activities, sweet drink consumption and anthropometry: results from a prospective European study. Eur J Clin Nutr 68, 223-228.

46. Roberts C, Freeman J, Samdal O et al. (2009) The Health Behaviour in School-aged Children (HBSC) study: methodological developments and current tensions. Int $\mathrm{J}$ Public Health 54, Suppl. 2, 140-150.

47. Albar SA, Alwan NA, Evans CE et al. (2014) Is there an association between food portion size and BMI among British adolescents? Br J Nutr 112, 841-851.

48. Börnhorst C, Huybrechts I, Ahrens W et al. (2013) Prevalence and determinants of misreporting among European children in proxy-reported $24 \mathrm{~h}$ dietary recalls. Br J Nutr 109, 1257-1265.

49. Fisher JO, Johnson RK, Lindquist C et al. (2000) Influence of body composition on the accuracy of reported energy intake in children. Obes Res $\mathbf{8}, 597-603$.

50. Moore LC, Harris CV \& Bradlyn AS (2012) Exploring the relationship between parental concern and the management of childhood obesity. Matern Child Health J 16, 902-908.

51. Burrows TL, Truby H, Morgan PJ et al. (2013) A comparison and validation of child versus parent reporting of children's energy intake using food frequency questionnaires versus food records: who's an accurate reporter? Clin Nutr $\mathbf{3 2}$, 613-618.

52. Bhaskaran K \& Smeeth L (2014) What is the difference between missing completely at random and missing at random? Int J Epidemiol 43, 1336-1339.

53. Wijnhoven TMA, van Raaij JMA, Sjöberg A et al. (2014) WHO European Childhood Obesity Surveillance Initiative: school nutrition environment and body mass index in primary schools. Int J Environ Res Public Health 11, 11261-11285.

54. Wijnhoven TMA, van Raaij JMA, Spinelli A et al. (2014) WHO European Childhood Obesity Surveillance Initiative: body mass index and level of overweight among 6-9-yearold children from school year 2007/2008 to school year 2009/2010. BMC Public Health 14, 806. 